\title{
Plasma Estrogens in Childhood and Puberty under Physiologic and Pathologic Conditions
}

\author{
F. Bidlingmaier, M. Wagner-Barnack, O. Butenandt, and D. KnorR ${ }^{[27]}$
}

Department of Endocrinology, Childrens' Hospital of the University of Muenchen, Muenchen, West Germany

\section{Extract}

Plasma concentrations of estrone and estradiol were determined by radioimmunoassay of cord blood from 17 neonates and of venous blood of 15 neonates, 61 boys and 69 girls of all developmental stages, 27 healthy women, 20 healthy men, and 89 male and female adolescents with different disorders of sexual development.

In cord blood both estrone and estradiol averaged $15,000 \mathrm{pg} / \mathrm{ml}$. Blood drawn from neonates shortly after birth showed levels between 300 and $500 \mathrm{pg} / \mathrm{ml}$. These levels fell to $5-15 \mathrm{pg} / \mathrm{ml}$ within a few days after birth, which is the normal range for both sexes up to 7 years. Before puberty, estrone rises earlier in girls than in boys. The increase of estradiol follows the onset of puberty. Boys reach adult levels in stage $I V$, whereas girls in stage $V$ still have lower estrogen levels than mature women.

We did not find higher levels in 29 adolescents with gynecomastia than in normal adolescents at the same stage of puberty. We observed abnormally high estrogens in children with congenital adrenal hyperplasia, but, in spite of some very high levels, we did not observe premature thelarche or gynecomastia in children with this disease. Six females and 10 males with panhypopituitarism, aged from 10 to 19 years, revealed low values within the infantile range. Six boys between 5 and 14 years who suffered from anorchia had very low levels of estrogen, especially estradiol (which was nearly undetectable). In contrast to patients with functioning testicle tissue, the patients with anorchia did not show any increase of estrogens after stimulation with human chorionic gonadotropin. Abnormally low levels were found in females with Turner's syndrome, but only in those with 45 , XO karyotype. Patients with 45 , $\mathrm{XO} / 46, \mathrm{XX}$, or $46, \mathrm{XXp}^{-}$karyotype had high levels of estrogen which corresponded to clinical signs of advanced puberty.

\section{Speculation}

As demonstrated by our results, the radioimmunologic method enables us to measure the low estrogen levels which are found in children. This will permit a more intensive examination of the pituitary-gonadal and pituitary-adrenal interrelation in the future.

\section{Introduction}

Still little is known about estrogens in childhood. The exact determination of these hormones in biologic ma- terial encountered considerable methodologic difficulties. Color reactions, such as the Kober reaction and its various modifications, can be used only for the determination of urinary estrogens. Because of their low 
specificity, color reactions lead to unclear or even contradictory results, especially during the period of low estrogen excretion before puberty. Methods developed later for measuring plasma estrogens, gas chromatography $[2,19]$ or double isotope derivative technique [3], are not applicable in children and adolescents because of the large quantities of plasma necessary. The introduction of radioimmunologic methods in steroid analysis, using highly specified antibodies against estrogens, made it possible to determine these hormones on the picogram range in large series. Thus, low plasma levels of estrogens as found in children can be determined. Although many studies on plasma estrogens in adults have been published since 1969 , there has been a lack of material presented about conditions in children and adolescents. The first results on plasma estradiol in girls were presented by Jenner et al. in 1972 [6]. During the preparation of this paper, Saez et al. [15] reported on levels of plasma estrogens before puberty. The present paper presents our studies on plasma estrone and plasma estradiol in both sexes before and during puberty and also findings in some disorders of sexual maturation. We have developed a highly specific radioimmunologic method which enables us to measure low levels in infants from reasonably small plasma quantities.

\section{Materials}

Antibodies against estrogens were obtained by immunization of rabbits with $17 \beta$-estradiol hemisuccinate linked covalently to bovine serum albumin. The antiserum with the highest specificity was used without further treatment in a dilution of $1 / 4,000$. Estrone and estradiol were evenly bound. The affinity of the antiserum to estriol was only $3 \%$. A cross-reaction with nonphenolic steroids was not observed in physiologic ranges. Extraction and purification of plasma estrogens and their radioimmunologic determination were done with the following reagents: anesthetic grade diethyl ether, methanol and benzene, analytical grade, $\mathrm{KH}_{2} \mathrm{PO}_{4}$, and $\mathrm{Na}_{2} \mathrm{HPO}_{4} \cdot 2 \mathrm{H}_{2} \mathrm{O}$ by Soerensen and $\mathrm{NaN}_{3}$ [20], Sephadex LH20, and dextran T70 [21], $\gamma$-globulin from bovine serum Cohn II 98\%, and Norit A [22]. $\left(6,7-{ }^{3} \mathrm{H}\right)$ Estrone $(43 \mathrm{Ci} / \mathrm{mmol})$ and $\left(6,7 \cdot{ }^{3} \mathrm{H}\right)$ estradiol (40 Ci/mmol) were supplied by Amersham/Searle [23]. In order to count radioactivity we used a liquid scintillation counter [24]. The radioimmunoassay was performed in disposable glass tubes, $11 \times 75 \mathrm{~mm}$. All glass equipment was washed in methanol before use and after drying contaminating material was eliminated by heating at $500^{\circ}$ in an oven $[9,25]$.

The assay solutions used consisted of $(1)$ buffer at pH 7.2: $2.68 \mathrm{~g} \mathrm{KH}_{2} \mathrm{PO}_{4}, 8.35 \mathrm{~g} \mathrm{Na}_{2} \mathrm{HPO}_{4} \cdot 2 \mathrm{H}_{2} \mathrm{O}, 0.32 \mathrm{~g}$ $\mathrm{NaN}_{3}, 1.0 \mathrm{~g} \gamma$-globulin, and distilled water to make $1,000 \mathrm{ml}$; (2) charcoal-dextran mixture: $0.5 \mathrm{~g}$ Norit A, $0.05 \mathrm{~g}$ dextran T70, and buffer to make $100 \mathrm{ml}$. Dilution of antiserum was likewise performed with the mentioned buffer.

\section{Patients and Study Materials}

Normal values were determined in cord blood from 17 healthy neonates and in venous blood of 15 neonates, 61 boys, and 69 girls of all ages and developmental stages. Some of these were outpatients with minor illness which required blood sampling for other reasons; others were healthy children of hospital personnel. The adult values were derived from 27 healthy women between the ages of 23 and 35 who were not taking contraceptive pills, and from 20 healthy men between the ages of 25 and 45 . In the study of plasma estrogens in sexual maturation disorders we used blood samples of patients from our endocrinology clinic: 29 boys with marked gynecomastia, 12 male and 17 female patients with congenital adrenal hyperplasia, 10 male and 6 female patients with panhypopituitarism, 6 patients with anorchia, and 10 patients with Turner's syndrome. The blood was drawn between $9 \mathrm{AM}$ and $4 \mathrm{PM}$, heparinized, and centrifuged. Plasma was stored at $-15^{\circ}$ until processing.

\section{Methods}

\section{Preparation of Plasma Samples}

Aliquots of $0.02-4.0 \mathrm{ml}$ plasma were added to 800 cpm tritiated estrone and estradiol to control procedural losses. This was followed by the extraction with ether, $2 \times 10 \mathrm{ml}$. The ether extracts were washed in 10 $\mathrm{ml}$ distilled water and evaporated under nitrogen. Further purification was performed using the method of Mikhail et al. [13] on Sephadex LH20 with benzenemethanol, $85 / 15$, as the solvent. The estrone and the estradiol fractions of 4 and $5 \mathrm{ml}$, respectively, were collected separately and evaporated under nitrogen. The dry residues were dissolved in $250 \mu \mathrm{l}$ buffer. Of this solution, $2 \times 100 \mu l$ were pipetted into clean glass assay tubes for double assay. Twenty-five microliters served as control for radioactive recovery and were counted for a total of 5,000 counts. 


\section{Standards}

Samples of $250 \mu 1$ defined estrone and estradiol solutions of from 0 to $300 \mathrm{pg} / 100 \mu \mathrm{l}$ buffer were transferred into tubes which held the dry residues of 4 and $5 \mathrm{ml}$ of pure column eluate, respectively, in accordance with the estrogen fractions. After being shaken for 15 $\min , 2 \times 100 \mu l$ were transferred into fresh tubes which were then run through the radioimmunoassay with the samples.

\section{Radioimmunoassay}

Next, 10,000 cpm tritiated estrone and estradiol, respectively, in $100 \mu \mathrm{l}$ buffer, were pipetted into the standards and into the samples, which were adequate for $40 \%$ of the plasma extract. $500 \mu \mathrm{l}$ of antibody solution was added and after a brief shaking the mixture was incubated in an ice bath for $2 \mathrm{hr}$. In pilot tests an incubation temperature of $0^{\circ}$ led to a higher degree of binding than the usual temperature of $4^{\circ}$ or room temperature. Attempts which extended beyond the incubation period demonstrated only a $4 \%$ increase of the steroid binding between $60 \mathrm{~min}$ and 16 hr. Separation of bound and unbound steroids was performed with $500 \mu l$ charcoal-dextran mixture in buffer. After a further $10-\mathrm{min}$ incubation in an ice bath, the mixture was centrifuged for $10 \mathrm{~min}$ at 1,800 $\times g$ and $0^{\circ}$. The supernatant which represented the protein-bound estrogens was decanted into scintillation vials and counted for $5 \mathrm{~min}$. The standard curve was prepared by plotting the relative binding of the tritiated estrogens against the known amounts of estrone and estradiol.

The addition of $800 \mathrm{cpm}$ tritiated estrone and estradiol to plasma served to control losses during purification stages. Radioactive recovery was 70-90\% for both hormones and was taken into consideration when values were calculated.

\section{Results}

\section{Quality Control Data}

Each assay was controlled by processing a tube with $4 \mathrm{ml}$ distilled water (blank) and two tubes with different combinations of the two hormones. The values are presented in Table $I$. The reproducibility of results from day to day was controlled by testing pooled children's plasma on 10 different days (Table II). The blanks of 2.7 and $2.2 \mathrm{pg} / \mathrm{ml}$, respectively, were not subtracted before calculation of results. No blank was
Table I. Estrogen recovery data ${ }^{1}$

\begin{tabular}{lccc}
\hline & $\tilde{\chi}, \mathrm{pg} / \mathrm{ml}$ & $\mathrm{sD}, \mathrm{pg} / \mathrm{ml}$ & $\begin{array}{c}\text { Coefficient of } \\
\text { variation, \% }\end{array}$ \\
\hline Estrone & & & \\
$\quad$ Water (blank) & 2.72 & 2.39 & \\
Water $+25 \mathrm{pg} / \mathrm{ml}$ & 24.9 & 2.39 & 9.6 \\
$\quad$ Water $+50 \mathrm{pg} / \mathrm{ml}$ & 49.0 & 5.5 & 11.2 \\
Estradiol & & & \\
Water (blank) & 2.2 & 2.5 & \\
Water $+25 \mathrm{pg} / \mathrm{ml}$ & 25.6 & 2.9 & 11.5 \\
Water $+50 \mathrm{pg} / \mathrm{ml}$ & 51.2 & 5.3 & 10.4 \\
\end{tabular}

${ }_{1 \text { Twenty-seven assays were done for each experimental cate- }}$ gory.

higher than the lowest analysis value in any assay. Thus, $7 \mathrm{pg} / \mathrm{ml}$ could be distinguished from 0 .

\section{Plasma Estrogens under Physiologic Conditions}

\section{Neonates}

In cord blood of 17 neonates, mean levels of estrone and estradiol of $15,000 \mathrm{pg} / \mathrm{ml}$ ranging from 9,000 to $34,000 \mathrm{pg} / \mathrm{ml}$ for both sexes were found. Levels in blood drawn from scalp veins in neonates were much lower during the first minutes and hours of life, and displayed a rapid decrease thereafter (Fig. 1).

\section{Childhood and Puberty of Males}

Figure 2 shows levels of estrone and estradiol of healthy boys and men plotted against chronologic age. Up to 8 years of age we found values under $15 \mathrm{pg} / \mathrm{ml}$ of both hormones. In the next 5 years of age the values gradually increased to those of adult males. In most cases estrone exceeded estradiol. We found good correlation not only with bone age but also with testicle volume; however, the best correlation resulted from comparison of the values with the clinically evaluable stages of sexual development (Table III). These were estimated by Tanner's criteria [17].

\section{Childhood and Puberty of Females}

Up to the age of 7 years we did not find higher levels in girls than in boys (Fig. 3). However, during

Table II. Interassay reproducibility

\begin{tabular}{lcccc}
\hline & $\begin{array}{c}\text { No. of } \\
\text { assays }\end{array}$ & $\overline{\boldsymbol{x}}, \mathrm{pg} / \mathrm{ml}$ & $\mathrm{sD}, \mathrm{pg} / \mathrm{ml}$ & $\begin{array}{c}\text { Coefficient of } \\
\text { variation, } \%\end{array}$ \\
\hline Estrone & 10 & 26.6 & 2.8 & 10.5 \\
Estradiol & 10 & 30.1 & 3.3 & 10.9 \\
\hline
\end{tabular}




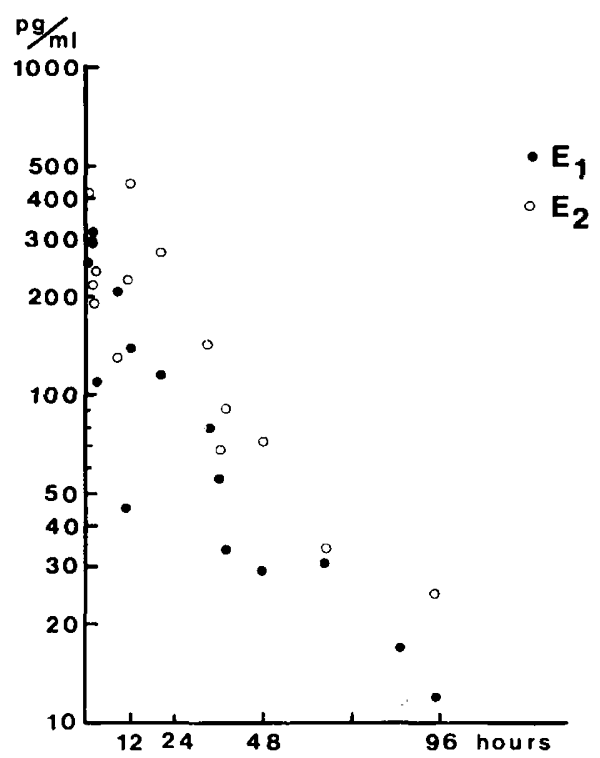

Fig. 1. Plasma estrogens in neonates during the first hours and days of life. $\bullet$ : estrone $\left(E_{1}\right)$; $\bigcirc$ : estradiol $\left(E_{2}\right)$.

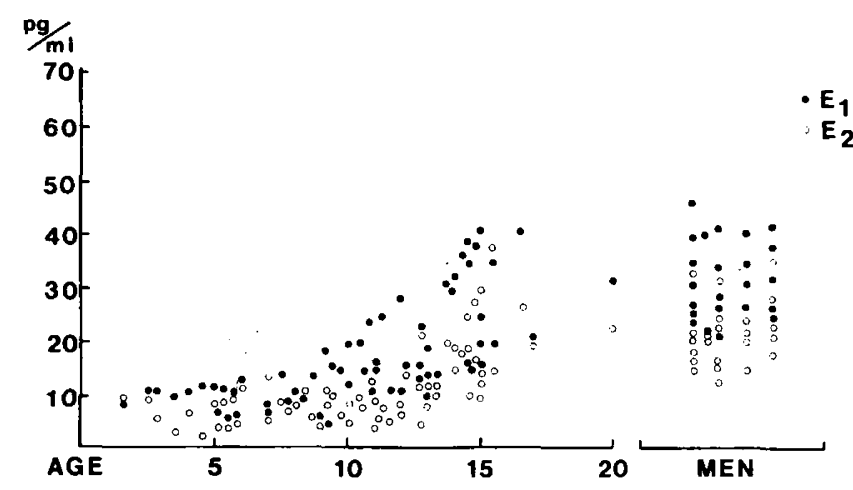

Fig. 2. Plasma estrogens in normal boys and men plotted against age. $\bullet$ : estrone $\left(E_{1}\right) ; 0$ : estradiol $\left(E_{2}\right)$.

Table III. Normal values for males

\begin{tabular}{lrrrr}
\hline $\begin{array}{c}\text { Maturational } \\
\text { stage }\end{array}$ & No. & $\begin{array}{c}\text { Estrone, }(\overline{\mathrm{x}} \pm \mathrm{s}), \\
\mathrm{pg} / \mathrm{ml}\end{array}$ & $\begin{array}{c}\text { Estradiol }(\overline{\mathrm{x}} \pm \mathrm{s}), \\
\mathrm{gg} / \mathrm{ml}\end{array}$ & Age, $(\overline{\mathrm{x}}) \mathrm{yr}$ \\
\hline Stage $I$ & 27 & $10.6 \pm 2.8$ & $7.5 \pm 2.8$ & 7.1 \\
Stage $I I$ & 12 & $15.6 \pm 3.1$ & $10.5 \pm 2.9$ & 12.1 \\
Stage $I I I$ & 6 & $21.4 \pm 2.0$ & $15.8 \pm 5.3$ & 13.6 \\
Stage $I V$ & 16 & $33.4 \pm 6.2$ & $21.9 \pm 7.8$ & 15.1 \\
Stage $V$ & 20 & $31.5 \pm 7.0$ & $20.7 \pm 5.3$ & $>18$ \\
\hline
\end{tabular}

the next 4 to 5 years, there was a sharp increase, far exceeding that of boys and reaching values of mature women. Values for different women at different days of their cycle are shown in Figure 3 on the right-hand side: low levels were found on the first and the last days; the highest levels are in the middle and form the midcycle peak. High levels also occur during the luteal phase. In order to group estrogen values for the girls in accordance with their stage of sexual development (Table IV) we used the criteria of Marshall and Tanner [12], modified by Jenner et al. [6]. Stage $V$ represents postmenarchial girls. A sharp increase is seen during puberty. The interpretation of a single value is becoming more and more difficult because of the increasing variation of estrogen levels with advancing maturation.

\section{Plasma Estrogens under Pathologic Conditions}

\section{Gynecomastia}

When comparison of estrogen values between 29 adolescent patients with gynecomastia and a normal group of healthy boys of the same age was made, we found some values in the upper normal range or slightly higher. Grouping in accordance with the classification of sexual development revealed no difference (Fig. 4).

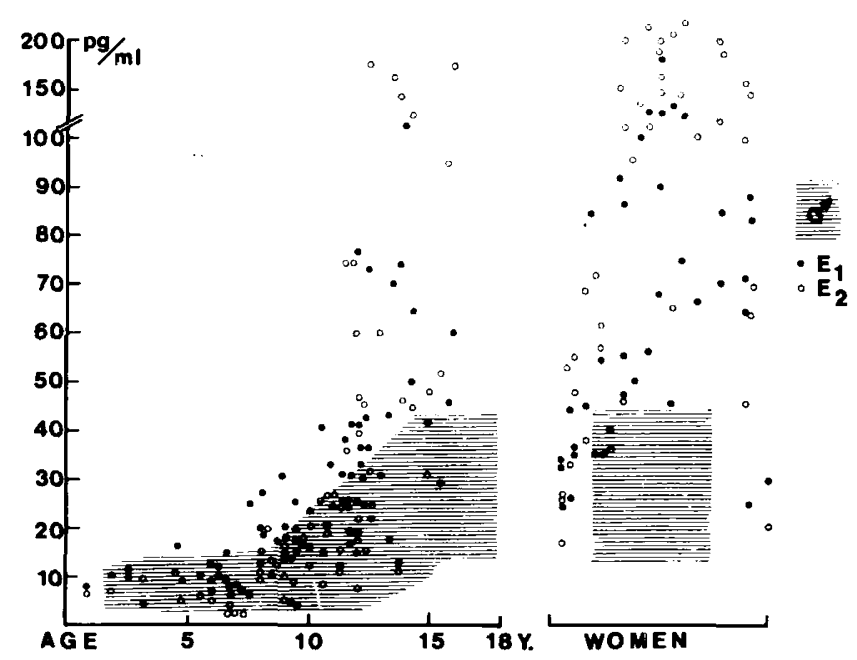

Fig. 3. Plasma estrogens in healthy females plotted against age. For comparison, the shadowed area shows the normal ranges for healthy males. $\bullet$ : estrone $\left(E_{1}\right)$; $\bigcirc$ : estradiol $\left(E_{2}\right)$.

Table IV. Normal values for females

\begin{tabular}{lrcccc}
\hline $\begin{array}{c}\text { Maturational } \\
\text { stage }\end{array}$ & No. & $\begin{array}{c}\text { Estrone }(\bar{x} \text { (range)), } \\
\mathrm{pg} / \mathrm{ml}\end{array}$ & $\begin{array}{c}\text { Estradiol } \\
(\overline{\mathbf{x}}(\mathrm{range})), \mathrm{pg} / \mathrm{ml}\end{array}$ & Age $(\overline{\mathrm{x}}), \mathbf{y r}$ \\
\hline Stage $I$ & 28 & $13.5(4-29)$ & $8.2(1-20)$ & 7.1 \\
Stage $I I$ & 8 & $21.3(10-33)$ & $16.4(10-24)$ & 10.5 \\
Stage $I I I$ & 10 & $30.4(15-43)$ & $25.3(7-60)$ & 11.6 \\
Stage IV & 12 & $36.1(16-77)$ & $46.8(21-85)$ & 12.3 \\
Stage $V$ & 10 & $61.5(29-77)$ & $111(34-170)$ & 14.5 \\
Women & 38 & $74.6(20-182)$ & $121(17-290)$ & 23 \\
\hline
\end{tabular}




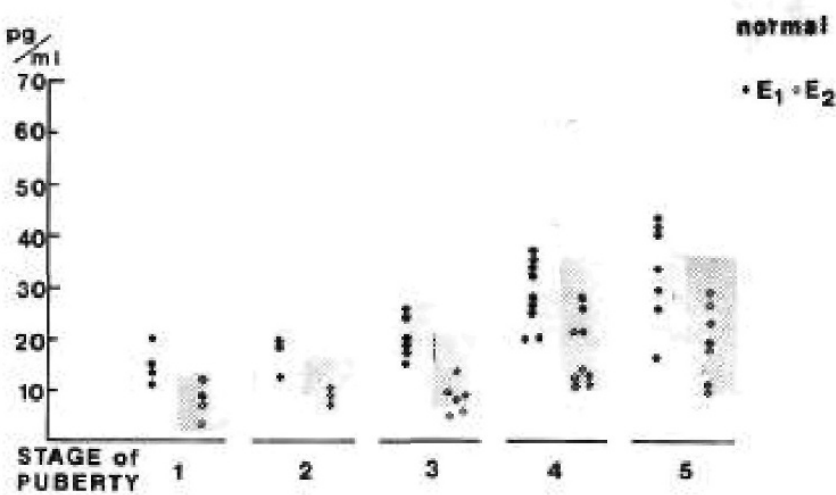

Fig. 1. Plasma estrogens in boys with gynecomastia plotted against stage of puberty compared with the normal ranges for healthy boys. $E_{1}$ : estrone; $E_{2}$ : estradiol.

\section{Congenital Adrenal Hyperplasia}

Abnormally high levels of estrogens were found in boys (Fig. 5) as well as in girls (Fig. 6) with congenital adrenal hyperplasia. Untreated or insufficiently treated patients had the highest values in both sexes.

\section{Panhypopituitarism}

Studies on 10 male and 6 female patients with panhypopituitarism (Figs. 5 and 6) revealed subnormal values in accordance with the infantile status of these patients.

\section{Anorchia}

Low values were found in six boys between 5 and 14 years of age with anorchia. Although estrone was still in the lower normal range, estradiol was barely detectable. In a 17-year-old adolescent boy who had received $250 \mathrm{mg}$ of depot-testosterone monthly for anorchia, both estrogens were found to be in the lower normal range (estrone $16 \mathrm{pg} / \mathrm{ml}$; estradiol $13 \mathrm{pg} / \mathrm{ml}$ ) at the end of such a 4-week period, but were significantly higher than in the other anorchia patients. Four days after another injection of $250 \mathrm{mg}$ depot-testosterone, both estrogens were elevated above the normal range of adult males (estrone $44 \mathrm{pg} / \mathrm{ml}$, estradiol $61 \mathrm{pg} / \mathrm{ml}$ ).

\section{Treatment with Gonadotropins}

No increase of estrogens resulted from treating anorchia patients with $10 \times 1,000 \mathrm{IU}$ human chorionic gonadotropin over a 5 -week period. On the contrary, 10 patients between 11 and 16 years who were treated for undescended testes or delayed puberty showed an average increase of estrone of $77 \%$ and of estradiol of $156 \%$ (Fig. 7).

\section{Turner's Syndrome}

Another group studied consisted of 10 girls with Turner's syndrome. This group was not uniform either in genotype or phenotype. The findings are presented in Table V.

\section{Discussion of Results}

The main purpose of this paper is to present new data on plasma estrogens in childhood and puberty.

In cord blood, estrone and estradiol ranged from 9,000 to $34,000 \mathrm{pg} / \mathrm{ml}$, which corresponds approximately to values which Abraham et al. [1] had measured radioimmunologically in women at the end of pregnancy. The comparatively low values in venous blood drawn from neonates shortly after birth, and the

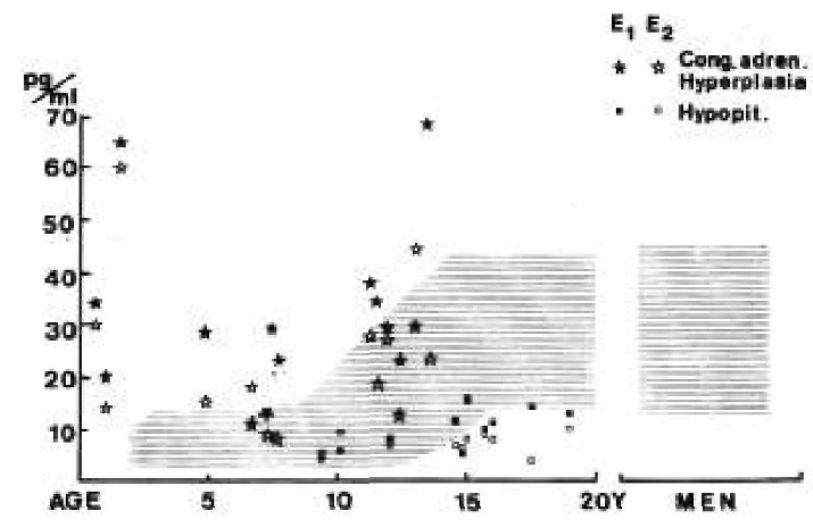

Fig. 5. Plasma estrogens in males with disorders of pubertal development plotted against age in comparison with normal ranges for males. Cong. adren. Hyperplasia: congenital adrenal hyperplasia; $E_{1}$ : estrone; $E_{2}$ : estradiol.

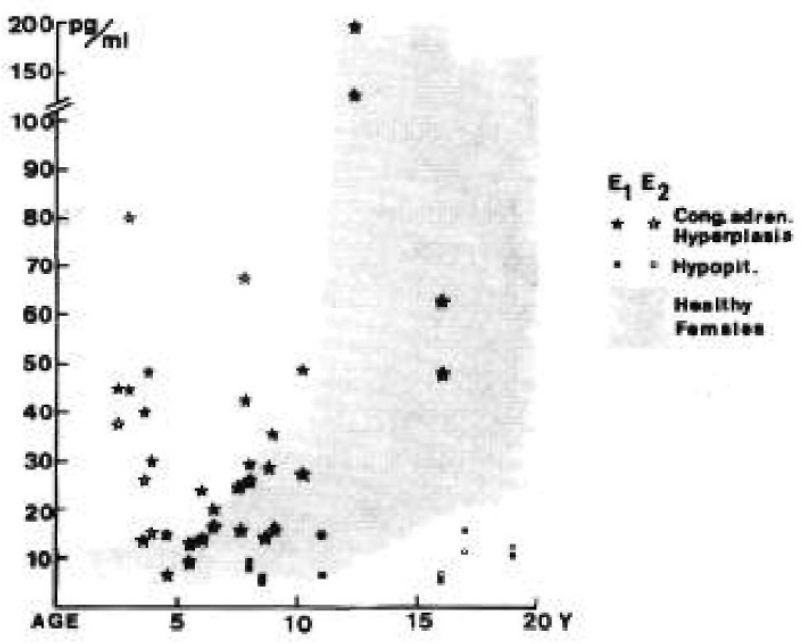

Fig. 6. Plasma estrogens in females with disorders of pubertal development plotted against age in comparison to normal ranges for females. Cong. adren. Hyperplasia: congenital adrenal hyperplasia; Hypopit. hypopituitarism; $E_{1}$ : estrone; $E_{2}$ : estradiol. 

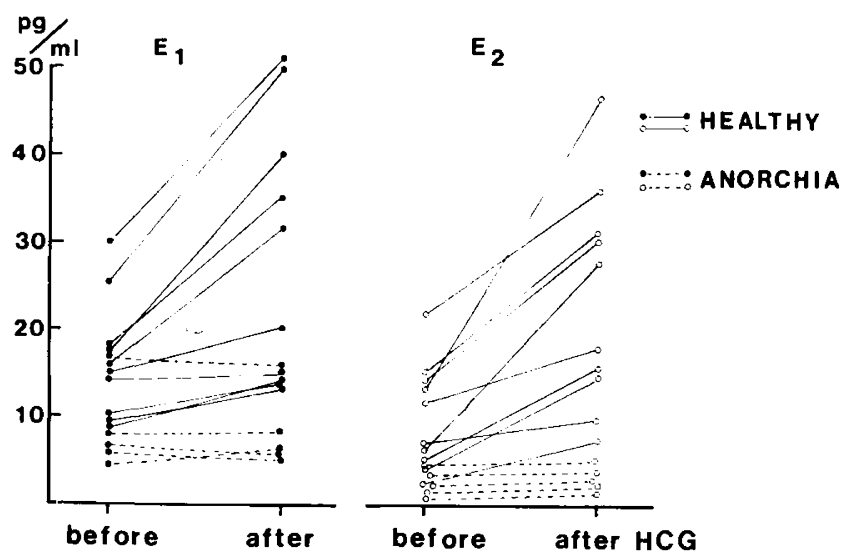

Fig. 7. Plasma estrogens in boys with functioning testicle tissue and in anorchia patients before and after stimulation with human chorionic gonadotropin (HCG). $E_{1}$ : estrone; $E_{2}$ : estradiol.

Table $V$. Estrogens in Turner's syndrome

\begin{tabular}{|c|c|c|c|c|c|}
\hline Patient & $\begin{array}{l}\text { Age, } \\
\mathrm{yr}\end{array}$ & Karyotype & $\begin{array}{l}\text { Es- } \\
\text { trone, } \\
\mathrm{pg} / \mathrm{ml}\end{array}$ & $\begin{array}{l}\text { Estra- } \\
\text { diol, } \\
\mathrm{pg} / \mathrm{ml}\end{array}$ & $\begin{array}{l}\text { Developmental } \\
\text { stage }\end{array}$ \\
\hline$R R$ & 8.5 & $45, \mathrm{XO}$ & 5.5 & 7.5 & Infantile \\
\hline$K M$ & 12 & $45, \mathrm{XO}$ & 12.5 & 14 & Infantile \\
\hline$M K$ & 14 & $45, \mathrm{XO}$ & 9 & 5 & Infantile \\
\hline$K J$ & 17 & $45, \mathrm{XO}$ & 11 & 7 & Infantile \\
\hline$K H$ & 17 & $45, \mathrm{XO}$ & 17 & 6 & Infantile \\
\hline$S H$ & 18 & $45, \mathrm{XO}$ & 15 & 17 & Infantile \\
\hline$B C$ & 12 & $\begin{array}{c}\text { 45, } \mathrm{XO} / 46, \\
\mathrm{XXp}^{-} \mathrm{q}^{-}\end{array}$ & 18 & 9.5 & Infantile \\
\hline$W J$ & 17 & $46, \mathrm{XXp}^{-}$ & 29 & 15 & $\begin{array}{l}\text { Pubes III, } \\
\text { Mammae } \\
\text { III }\end{array}$ \\
\hline$M B$ & 15 & $\begin{array}{l}45, \quad \mathrm{XO} / 46 \\
\mathrm{XX}\end{array}$ & 38 & 78 & $\begin{array}{l}\text { Pubes III, } \\
\text { Mammae } \\
\text { IV }\end{array}$ \\
\hline$D D$ & 16 & $\begin{array}{c}45, \mathrm{XO} / 46 \\
\mathrm{XXp}^{-} \mathrm{q}^{-}\end{array}$ & 44 & 28 & Pubes III \\
\hline
\end{tabular}

subsequent sharp decrease to the normal prepubertal range within 4 days, can be explained by the ability of the neonate as well as the fetus to rapidly conjugate or inactivate otherwise free estrogens.

The estradiol values for girls grouped in accordance with their stages of sexual maturation agree with the findings of Jenner et al. [6], who studied the change of estradiol levels during female puberty in detail using a radiommunologic method. Findings on estradiol levels for boys by Winter $e t$ al. [18] and Chopra $e t$ al. [4] also correspond to our findings of normal ranges of different maturation stages. To date no similar studies have been published on estrone. Personal communication with Bertrand [16] revealed that his group had similar values to ours for plasma estrone and plasma estradiol.
The early rise of estrone in both sexes coincides with the increase of dehydroepiandrosterone and its sulfate after adrenarche. This points to a correlation with maturation of the adrenal cortex. Bertrand's group [15] was able to show that estrone can be markedly suppressed by dexamethasone in girls with precocious puberty, in contrast to estradiol, which reacted very little. Kirschner and Knorr [7] made similar observations in their determination of estrone and estradiol excretions in urine of men before and after treatment with dexamethasone. Our patients with anorchia had estrone levels within the normal range because of their healthy adrenals, but estradiol was barely detectable and there was no reaction to gonadotropin stimulation. In contrast, all boys with functioning testicle tissue showed a rise of estrone and, more pronounced, of estradiol after human chorionic gonadotropin treatment. In all these patients an increase of testosterone of some $100 \%$ had occurred as could be expected according to the studies of Knorr [8] and Saez and Bertrand [14]. Up to now it has not been clear whether the gonadotropin stimulus really results in the estradiol secretion from the testes, or whether the estradiol level depends entirely on the testosterone and its partial aromatization.

No elevation of estrogens is necessary for development of pubertal gynecomastia. None of our gynecomastia patients had estrogen levels above the normal range for his stage of development. Also, in girls, breast development in stage II begins at low estrogen levels and it is only in stage $I V$, when the breast is almost mature, that the mean estrogen values exceed those of adult males.

High values, some far above the average, were found in children with congenital adrenal hyperplasia. This may be explained by the conversion of adrenal androgens to estrogens [11]. Untreated or insufficiently treated patients had the highest estrogens. In these patients we also found the highest 17-hydroxyprogesterone levels in plasma, using a gas chromatographic method [10]. In 1958 Eberlein et al. [5] had already demonstrated a correlation between estriol excretion in the urine and the excretion of 17-ketosteroids and pregnantriol in patients with congenital adrenal hyperplasia.

The low estrogen values in our patients with hypopituitarism correspond to expectations. In this clinically uniform group of pituitary infantile dwarfs, no stimulation of gonads or adrenals by the pituitary hormones was found.

Infantile values were also observed in girls with 
Turner's syndrome, but only in those with $45, \mathrm{XO}$ karyotype. Patients with $46, \mathrm{XXp}^{-}$karyotype or 45 , $\mathrm{XO} / 46, \mathrm{XX}$ and $45, \mathrm{XO} / 46, \mathrm{XXp}^{-} \mathrm{q}^{-}$-mosaic revealed levels markedly above the infantile range. This can be explained by the presence of hormonally active ovarian tissue.

The results of our study on plasma estrogens under physiologic and pathologic conditions are based mostly on single determinations and do not consider individual variations occurring in diurnal or other rhythms. Several determinations made in some of the women at regular intervals over 1 month revealed marked changes during the cycles. We can contribute little on possible cyclic changes before the menarche or in girls with precocious puberty. The further improvement of radioimmunologic tests will make possible determinations with smaller amounts of blood than are currently necessary. Longitudinal section studies will thus become feasible for younger patients.

\section{Summary}

The concentrations of plasma estrogens were determined by radioimmunoassay in males and females of all developmental stages. Sex differences could not be observed in patients under 8 years. Boys with pubertal gynecomastia revealed the same estrogen values as normal boys of the same stage of puberty. Elevated levels were found in congenital adrenal hyperplasia, and decreased levels in panhypopituitarism, anorchia, and Turner's syndrome.

\section{References and Notes}

1. Abraham, G. E., Odell, W. D., Edwards, R., and Purdy, J. M.: Solid-phase radioimmunoassay of estrogens in biological fluids: Steroid assay by protein binding. Acta Endocrinol. (Suppl.), 1+7: 332 (1970).

2. Attal, J., Hendeles, S. M., and Eik-Nes, K. B.: Determination of free estrone in blood plasma by gas-phase chromatography with electron capturc detection. Anal. Biochem., 20: 394 (1967).

3. BAIRD, D. T.: A method for measurement of estrone and estradiol-17 $\beta$ in peripheral human blood and other biologic fluids using ${ }^{35} \mathrm{~S}$ pipsyl chloride. J. Clin. Endocrinol., 28: 244 (1968).

4. Chopra, I. J., Abraham, G. E., Chopra, U., Solomon, D. H., AND ODELL, W. A.: Alterations in circulating estradiol-17 $\beta$ in male patients with Grave's disease. New Engl. J. Med., 286: 124 (1972).

5. Eberlein, W., Bongrovanni, A. M., and Francis, C. M.: A simplified method for the routine measurement of urinary estriol. J. Clin. Endocrinol., 18: 1274 (1958).

6. Jenner, M. R., Kelch, R. R., Kaplan, S. L., and Grumbach,
M. M.: Hormonal chancgs in puberty. IV. Plasma estradiol, LH, and FSH in prepubertal children, pubertal females and in precocious puberty, premature thelarche, hypogonadism and in a child with feminizing ovarian tumor. J. Clin. Endocrinol., 34: 521 (1972).

7. Kirschner, M. A., AND KNorr, D. W. R.: Suppression of androgen and oestrogen production in normal men. Acta Endocrinol., $70: 342$ (1972).

8. KNORR, D.: Über die Ausscheidung von freiem und glucuronsäuregebundenem Testosteron im Kindes-und Reifungsalter. Acta Endocrinol., 54: 215 (1967).

9. KNorr, D.: Ultrareine Glasgeräte durch Ausheizen bei $500^{\circ}$. Z. Klin. Chem. Klin. Biochem., 9: 175 (1971).

10. Knorr, D., Bidlingmaier, F., and Seidi, H.: Gaschromatographische Bestimmung des $17 \alpha \cdot$ Hydroxyprogesterons im Plasma mit Elektroneneinfangdetektor. Z. Anal. Chem., 259: 221 (1972).

11. MacDonald, P. C., Rombaut, R. P., and Sitteri, P. K.: Plasma precursors of estrogen. I. Extent of plasma $\Delta^{4}$-androstenedione to estrone in normal males and nonpregnant normal, castrate and adrenalectomized females. J. Clin. Endocrinol., 27: 1103 (1967).

12. Marshall, W. A., and Tanner, J. M.: Variations in pattern of pubertal changes in girls. Arch. Dis. Childhood, 44: 291 (1969).

13. Mikhail, G., Wu, C. H., Ferin, M., and Vande Wiele, R. L.: Radioimmunoassay of plasma estrone and estradiol. Steroids, 15: 333 (1970).

14. Saez, J. M., and Bertrand, J.: Studies on testicular function in children: Plasma concentrations of testosterone, dehydroepiandrosterone and its sulfate before and after stimulation with human chorionic gonadotrophin. Steroids, 12: 749 (1968).

15. Saez, J. M., Morera, A. M., and Bertrand, J.: Plasma concentration of estrone $\left(E_{1}\right)$ and estradiol $\left(E_{2}\right)$ before puberty in humans (Abstract). IVth International Congress of Endocrinology, June 1972.

16. Saez, J. M., Morera, A. M., and Bertrand, J.: Personal communication.

17. Tanner, J. M.: Wachstum und Reifung des Menschen (Thieme, Stuttgart, 1962).

18. Winter, J. S. D., Taraska, S., and Faiman, C.: The hormonal response to HCG stimulation in male children and adoles. cents. J. Clin. Endocrinol., 34: 348 (1972).

19. Wotiz, H. H., Charransol, G., and Smith, I. N'.: Gas chromatographic measurement of plasma estrogens using electron capture detector. Steroids, 10: 127 (1967).

20. Merck, AG, Darmstadt, Germany.

21. Pharmacia Fine Chemicals, Inc., Uppsala, Sweden.

22. Serva Feinbiochemika, GmbH, Heidelberg, Germany.

23. Amersham/Searle, Corporation, Arlington Heights, Ill.

24. Model 3320 Tri-Carb, Packard Instrument Company, Downer's Grove, Ill.

25. Model TA 500, Heraeus, GmbH, Hanau, Germany.

26. This research was supported by Deutsche Forschungsgemeinschaft, SFB 51 .

27. Requests for reprints should be addressed to: Frank BidingMAIER, M.D., Universitaets-Kinderklinik, D 8000 Muenchen 2, Lindwurmstr. 4, Muenchen, West Germany.

28. Accepted for publication June 20, 1973. 